\title{
FORMULATION AND OPTIMIZATION AND IN VITRO CHARACTERIZATION OF OLANZAPINE LIPOSOME
}

\section{G. NETHRA VANI ${ }^{*}$, M. ALAGUSUNDARAM ${ }^{2}$, K. B. CHANDRASEKAR ${ }^{3}$}

\author{
${ }^{1}$ Department of Pharmaceutical Sciences, Jawaharlal Nehru Technological University, Anantapur, Andhra Pradesh, ${ }^{2}$ Department of \\ Pharmaceutics, Ratnam Institute of Pharmacy, Nellore, Andhra Pradesh, ${ }^{3}$ Department of Chemistry, Jawaharlal Nehru Technological \\ University, Anantapur, Andhra Pradesh \\ Email: nethravani.g@gmail.com
}

Received: 17 May 2021, Revised and Accepted: 08 Jul 2021

\begin{abstract}
Objective: Olanzapine (OZ) is a thioeno benzodiazepine class second-generation or atypical antipsychotic that selectively binds to central dopamine D2 and serotonin (5-HT2c) receptors used for the treatment of schizophrenia and bipolar disorder. The present paper is aimed at developing an optimized liposome-loaded $\mathrm{OZ}$ as an approach for brain targeting through the nasal route for effective therapeutic management of schizophrenia.

Methods: The OZ liposomes were prepared by the thin-film hydration method. Various independent variable such as phospholipid, cholesterol and sonication time was optimized by using Design-Expert ${ }^{\circledR}$ Software to obtain the dependent variables of entrapment efficiency, vesicle size and zeta potential. The optimized formulation was predicted based on the response obtained by the point prediction method.

Results: The entrapment efficiency of the formulation was range between 72.9 and $85.1 \%$. The average particle size of all the 15 experimental runs lies between the minimum and maximum values of the size 258.33 to $325.32 \mathrm{~nm}$, respectively. The zeta potential ranges from-27.53 to-11.46 mV. The optimized formulation for characterized for its morphology by Transmission Electron Microscopy (TEM). In vitro release studies of OZ-loaded liposomal formulation was carried by dialysis sac method using $\mathrm{pH} 7.4$ phosphate buffer (PBS) as a medium. The maximum release was found to be $98.43 \pm 1.2 \%$ up to $24 \mathrm{~h}$. The $\mathrm{R}^{2}$ zero-order kinetics and Korsmeyer-Peppas model was found to be 0.9919 and 0.9664 , respectively. The zero-order shows the best-fit model with a highest $\mathrm{R}^{2}$ value exhibiting better correlation and the ' $\mathrm{n}$ ' value was also found to be 0.85 ; indicating both diffusioncontrolled and swelling-controlled drug release that is anomalous transport.
\end{abstract}

Conclusion: The results, clearly states that the prepared formulations justify the parameters and OZ might be a suitable candidate to target the brain through nasal delivery.

Keywords: Design expert, Entrapment efficiency, Lipid film hydration, Liposomes, Schizophrenia

(C) 2021 The Authors. Published by Innovare Academic Sciences Pvt Ltd. This is an open access article under the CC BY license (https://creativecommons.org/licenses/by/4.0/) DOI: https://dx.doi.org/10.22159/ijap.2021v13i5.42085. Journal homepage: https://innovareacademics.in/journals/index.php/ijap

\section{INTRODUCTION}

Psychotic disorders included severe mental diseases with disordered thinking, loss of connections with reality due to delusions and/or hallucinations. Schizophrenia is one of the wellestablished and common psychotic disorders [1]. Majority of the schizophrenia cases require psychosocial treatment along with pharmacotherapy [2]. The anti-schizophrenic drugs generally have poor bioavailability apart from their adverse drug reactions [3]. The lack of drug availability at the site of action is mainly attributed to the blood-brain barrier (BBB), which restricts the penetration of drugs into the central nervous system (CNS) [4]. Hence, many efforts are being made to develop novel drug delivery systems such as solid-lipid nanoparticles, nanoemulsions, liposomes and polymeric nanoparticles to transport the drug to the brain $[4,5]$.

Liposomes have desirable biological properties, including biocompatibility and biodegradability [6]. Liposomes, due to their subcellular size allow relatively higher intracellular uptake than other particulate systems. Apart from other routes of drug administration, nano-sized drug-loaded systems can be delivered through the nasal route. Upon nasal instillation of the formulation, the drug is directly transported to the brain by circumventing BBB and provide a rapid onset of action due to the presence of high vascularisation [7]. The drugs can reach the central nervous system through extracellular or intracellular transport along olfactory nerves and also by the trigeminal pathway [8]. Liposomes through intranasal administration, provide benefits in terms of improved penetration into the brain [9]. Liposomes are increasingly being explored for the intranasal delivery of drugs and vaccines for enhanced systemic availability and targeting. Some examples of the drugs tried.

Olanzapine (OZ) is a thioeno benzodiazepine class second-generation or atypical antipsychotic that selectively binds to central dopamine D2 and serotonin (5-HT2c) receptors used for the treatment of schizophrenia and bipolar disorder $[10,11]$. It has poor bioavailability due to hepatic first-pass metabolism and low permeability into the brain due to efflux by P-glycoproteins. It was approved by the FDA for the management of schizophrenia and the treatment of moderate to severe mania associated with bipolar disorders [12]. Following oral administration, the drug suffers from low brain permeability due to efflux by P-glycoproteins in the blood-brain barrier (BBB) as well as extensive hepatic first-pass metabolism where $40 \%$ of the dose is approximately metabolized before reaching the systemic circulation [13]. Increasing the dosage and/or dosing frequencies is commonly associated with extrapyramidal effects, orthostatic hypotension, weight gain, dry mouth, tremors, akathisia and somnolence.

Therefore, in the present study, liposome-loaded $\mathrm{OZ}$ is prepared and optimized using Box Behnken Design (BBD) and target the brain via the intranasal route, to improve the bioavailability and minimize its peripheral adverse effects owing to its direct delivery to the brain.

\section{MATERIALS AND METHODS}

\section{Materials}

Olanzapine (OZ) was a gift sample from MSN Laboratories Pvt Ltd, Hyderabad. phosphatidylcholine (PC) was obtained as a gift sample from LIPOID, Germany. Cholesterol was procured from Sigma Aldrich, India. All other reagents and chemicals used were of laboratory/analytical grade.

\section{Preparation of OZ loaded liposomes}

OZ loaded conventional liposomes consisting of phosphatidylcholine (PC) and cholesterol were prepared by lipid film hydration method as per the literature with slight modification [14]. Accurately weighed amount of drug, PC and cholesterol were added to a $250 \mathrm{ml}$ round 
bottom flask (RBF) and then dissolved in $10 \mathrm{ml}$ of chloroform. The RBF was attached to the rotavapour (Superfit, India) and maintained at 40 ${ }^{\circ} \mathrm{C}$. The rotation speed of RBF was adjusted to $40 \mathrm{rpm}$ and a vacuum was applied for $20 \mathrm{~min}$ to aid the evaporation of chloroform and to form a thin layer of lipids on the inner wall of the RBF. The vacuum was released and RBF was kept in a vacuum desiccator for $24 \mathrm{~h}$ to completely remove the residual traces of chloroform. Phosphate buffer pH $6.4(10 \mathrm{ml})$ was added as the hydration media and lipid film was removed by the hand-shaken method in a water bath at $40^{\circ} \mathrm{C}$. A milky white uniform multi-lamellar liposomal suspension was obtained, which were further reduced in size by probe sonication (in an ice bath) at amplitude $60 \%$, time $5 \mathrm{~min}$ and 2 pulse/s. Uniform suspension of liposomes obtained was transferred to sterilized vials and stored at 4 ${ }^{\circ} \mathrm{C}$ until use [15].

\section{Optimization and validation of the experimental design}

The liposome formulations contained different variables such as lipid ratio and lipid to drug ratio. The liposomal formulation was optimized by using Design-Expert® Software Version 11-StatEase, Inc. Box-Behnken can be used to derive three factors (X1, X2 and X3) and three levels $(-1,0,+1)$ design can be developed by the inclusion of a central point. The present study consists of 3 variables/factors $\left(\mathrm{X}_{1}\right.$ : Phospholipid and $\mathrm{X}_{2}$ : Cholesterol $\mathrm{X}_{3}$ : Sonication time) and the response variables were $R_{1}$ : Entrapment Efficiency, $\mathrm{R}_{2}$ : Size, $\mathrm{R}_{3}$ : Zeta Potential. The experimental trials being performed at all 15 possible combinations, as the batch containing central point was prepared three times to compute the results (table 1 ).

Table 1: Selected level of independent and dependent variables used for BBD for the preparation of liposomes

\begin{tabular}{|c|c|c|c|}
\hline Factors/Independent variables & Name of the variables & Minimum & Maximum \\
\hline $\mathrm{X}_{1}$ & Lipid (mg) & 300.00 & 500.00 \\
\hline $\mathrm{X}_{2}$ & Cholesterol (mg) & 20.00 & 80.00 \\
\hline $\mathrm{X}_{3}$ & Sonication time $(\mathrm{min})$ & 5.00 & 15.00 \\
\hline Responses/Dependent variables & Constraints & & \\
\hline $\mathrm{R}_{1}$ : Entrapment Efficiency (\%) & Maximum & & \\
\hline $\mathrm{R}_{2}:$ Size $(\mathrm{nm})$ & Minimum & & \\
\hline $\mathrm{R}_{3}$ : Zeta potential $(\mathrm{mV})$ & In range & & \\
\hline
\end{tabular}

\section{Entrapment efficiency}

The entrapment efficiency of OZ loaded liposomes was determined by separating the free drug from the liposomes. The unentrapped drug was separated from the entrapped drug by ultracentrifugation of the risperidone loaded liposomal formulation at $60,000 \mathrm{rpm}$ for one hour. Pellet of the entrapped drug was collected and supernatant (free drug) was separated by decantation. Further, the pellets were dispersed in phosphate buffer $\mathrm{pH} 6.4(3 \mathrm{ml})$ and vortexed for $10 \mathrm{~min}$ followed by bath sonication for $5 \mathrm{~min}$ for complete dispersion of liposomes. A $50 \mu \mathrm{l}$ of dispersed liposomes were taken and then $50 \mu$ l of $10 \%$ Triton-X was added to break the liposomes and release the entrapped drug. The volume was made up to $1 \mathrm{ml}$ with phosphate buffer $\mathrm{pH}$ 6.4. The drug content was analysed in both pellets and the supernatant by the UV spectrometry method at $273 \mathrm{~nm}$ [16]. The entrapment efficiency was calculated by the formula [17]

$$
\text { Entrapment efficiency }(\%)=\frac{\mathrm{Ct}-\mathrm{Cf}}{\mathrm{Ct}} \times 100
$$

Where $C_{t}$ and $C_{f}$ are the concentrations of the total and free drug, respectively.

\section{Vesicle size and zeta potential}

The mean vesicle size of OZ loaded liposomes was determined by the dynamic light scattering method using Malvern NanozS (Malvern Instruments Ltd., UK). The system was equipped with a $4 \mathrm{~mW}$ Helium/Neon laser at $633 \mathrm{~nm}$ wavelength and measured the liposome sample with non-invasive backscatter technology at a detection angle of $173^{\circ}$. Zeta potential measurement was carried out using the same instrument by the Laser-Doppler electrophoresis technique. Liposomal samples were diluted with Milli-Q water and all measurements were carried out in at $25 \pm 1^{\circ} \mathrm{C}$.

\section{Morphological studies by transmission electron microscopy} (TEM)

To study the surface characteristics of the liposomes and individual vesicle size TEM analysis was carried out by negative staining method. A sample containing $50 \mu \mathrm{l}$ of liposomes dropped in the parafilm and copper grid was kept above the samples and waited for $1 \mathrm{~min}$, then the copper grid was placed in the $2 \%$ phosphotungstic acid and waited for $30 \mathrm{~s}$. Afterward, copper grid was taken out and dried with the help of tissue paper and then placed under the TEM microscope. The picture was taken at various magnifications $(10.0$ $\mathrm{k}$ ) and accelerating voltage $80 \mathrm{kV}$ and data was analysed.

\section{In vitro release studies}

In vitro release studies of $\mathrm{OZ}$ loaded liposomal formulation was carried by dialysis sac method using $\mathrm{pH} 7.4$ phosphate buffer (PBS) as a medium. The dialysis sac membrane was previously soaked for $12 \mathrm{~h}$ and fixed at one side of the diffusion cell, having openings on both sides. A $25 \mathrm{ml}$ of diffusion medium was taken in a $50 \mathrm{ml}$ beaker and kept for stirring at $300 \mathrm{rpm}$ on a magnetic stirrer at room temperature. OZ loaded liposomal suspension (1 ml) was placed on the dialysis sac and the diffusion cell was immersed in a diffusion medium [15]. At intervals of 1, 2, 4, 6, 8, 12, 16, 20 and $24 \mathrm{~h}, 1 \mathrm{ml}$ of the dialysed sample was withdrawn and an equal volume of PBS pH 7.4 was replaced to maintain sink condition. The samples were analysed using UV spectrometry at $273 \mathrm{~nm}$. The experiment was performed and the percentage of drugs released was calculated. For evaluating the kinetics and mechanism of drug release from the liposomes, Korsmeyer-Peppas model, Higuchi model, first-order and zero-order mathematical models were used, and best-fitted model was selected based on high correlation coefficient (R) value for the release data.

\section{RESULTS AND DISCUSSION}

\section{Formulation design of $\mathrm{OZ}$ liposomes}

OZ liposomes were prepared by the lipid film hydration method. To optimize the formulation parameters and to obtain a formulation with maximum entrapment with better in vitro release, the Box Behnken Design (BBD) was used. A total of 15 experimental runs for the prepared formulations with 3 centre points has been formulated. Responses obtained from these runs were shown in table 2. Batches were prepared based on the experimental plan from Design-Expert® Software. The formulations were evaluated for Entrapment efficiency, zeta potential and zeta potential [18]. The results obtained from all the formulations were fed into the Design-Expert $₫$ Software to generate a study design and the response surface plots. The quadratic model obtained for the formulations was suitably fitted. The values of R2, SD, and \% coefficient of variation of each of the 3 responses are shown in table 3. The effect of independent variables on phospholipid, Cholesterol, and sonication time is presented on a three-dimensional graph (fig. 1). Moreover, a quantitative comparison that is resulted from experimental values of the responses with that of the predicted values can also be analyzed from fig. 2 .

Response 1 (Y1): effect of independent variables on \% entrapment efficiency

The entrapment efficiency of the formulation was a range between 72.9 and $85.1 \%$ [19]. The Model F-value of 215.35 implies the model 
is significant. There is only a $0.01 \%$ chance that an F-value this large could occur due to noise. P-values $<0.05$ indicate model terms are significant. In this case, $\mathrm{X}_{1}, \mathrm{X}_{2}, \mathrm{X}_{3}, \mathrm{X}_{1} \mathrm{X}_{2}, \mathrm{X}_{1} \mathrm{X}_{3}, \mathrm{X}_{2}{ }^{2}, \mathrm{X}_{2}{ }^{2}, \mathrm{X}_{3}{ }^{2}$ are significant model terms. The regression equation for entrapment efficiency is

$\% \quad \mathrm{EE}=+80.93+2.91 \quad \mathrm{X}_{1}+3.01 \quad \mathrm{X}_{2}+0.975 \quad \mathrm{X}_{3}-1.45 \quad \mathrm{X}_{1} \mathrm{X}_{2}+0.9750$ $\mathrm{X}_{1} \mathrm{X}_{3}+0.0750 \mathrm{X}_{2} \mathrm{X}_{3}-1.84 \mathrm{X}_{1}^{2}+1.36 \mathrm{X}_{2}^{2}-2.12 \mathrm{X}_{3}^{2}$

The positive effect on entrapment efficiency was found in correlation with lipid and cholesterol concentration. A significant effect was also found with interaction effects of lipid and cholesterol [20-22].

\section{Response 2 (Y2): effect of independent variables on size}

The average particle size of all the 15 experimental runs was found to be $299.20 \mathrm{~nm}$; hence these value lies between the minimum and maximum value of the size 258.33 to $325.32 \mathrm{~nm}$, respectively [23]. The Model F-value of 63.47 implies the model is significant. There is only a $0.01 \%$ chance that an F-value this large could occur due to noise. P-values less than 0.0500 indicate model terms are significant. In this case, $\mathrm{X}_{1}, \mathrm{X}_{2}, \mathrm{X}_{3}, \mathrm{X}_{1} \mathrm{X}_{2}, \mathrm{X}_{1} \mathrm{X}_{3}, \mathrm{X}_{2} \mathrm{X}_{3}, \mathrm{X}_{2}{ }^{2}, \mathrm{X}_{3}{ }^{2}$ are significant model terms. The Lack of Fit F-value of 6.31 implies the Lack of Fit is not significant relative to the pure error. There is a $13.99 \%$ chance that a Lack of Fit F-value this large could occur due to noise. The Predicted $\mathrm{R}^{2}$ of 0.8726 is in reasonable agreement with the Adjusted $\mathrm{R}^{2}$ of 0.9757. All the factors have an effect size of the liposomes as the increase in sonication time the size reduction has been found in several formulations. The regression equation for size is

Size $=+294.87-6.83 \quad X_{1}-20.15 \quad X_{2}-4.66 \quad X_{3}+9.42 \quad X_{1} X_{2}-5.78 \quad X_{1} X_{3}-5.22$ $\mathrm{X}_{2} \mathrm{X}_{3}-0.5987 \mathrm{X}_{1}^{2}-11.20 \mathrm{X}_{2}{ }^{2}+19.92 \mathrm{X}_{3}{ }^{2}$

\section{Response 3 (Y3): effect of independent variables on zeta potential}

The zeta potential of the 15 formulations ranges from-27.53 to$11.46 \mathrm{mV}$ [24-26]. The Model F-value of 103.24 implies the model is significant. There is only a $0.01 \%$ chance that an F-value this large could occur due to noise. P-values $<0.05$ indicate model terms are significant. In this case, $\mathrm{X}_{2}, \mathrm{X}_{3}, \mathrm{X}_{3}{ }^{2}$ are significant model terms. Values $>0.1$ indicate the model terms are not significant. The Lack of Fit F-value of 10.27 implies there is a $9.00 \%$ chance that a Lack of Fit F-value this large could occur due to noise.

Zeta potential $=-17.43+0.5612 \quad \mathrm{X}_{1}+1.11 \quad \mathrm{X}_{2}-6.99 \quad \mathrm{X}_{3}-0.5800 \quad \mathrm{X}_{1} \mathrm{X}_{2}-$ $0.3125 \mathrm{X}_{1} \mathrm{X}_{3}-0.2800 \mathrm{X}_{2} \mathrm{X}_{3}-+0.1163 \mathrm{X}_{1}^{2}+0.3587 \mathrm{X}_{2}^{2}-2.70 \mathrm{X}_{3}^{2}$

\section{Optimization and validation}

The response surface plots elucidate the effect of variables on the responses and interactions between the variables. Minimum and maximum levels were provided for each response parameter, the goals are combined into an overall desirability function $(0.971)$. The optimized formulation was fixed by the point prediction method. The list of solutions was sorted with the highest desirability. The contour plot for the optimized formulation and its desirability was shown in fig. 3. Analysis of variance (ANOVA) was used to identify the significant effect of factors on response regression coefficients [15]. To evaluate the chosen experimental design, the optimized formulations were prepared and subjected to evaluation parameters. The resulting experimental values were compared with predicted values. The constraints criteria were maximum entrapment of drug in formulation, optimum zeta potential, the minimum size of liposomes.
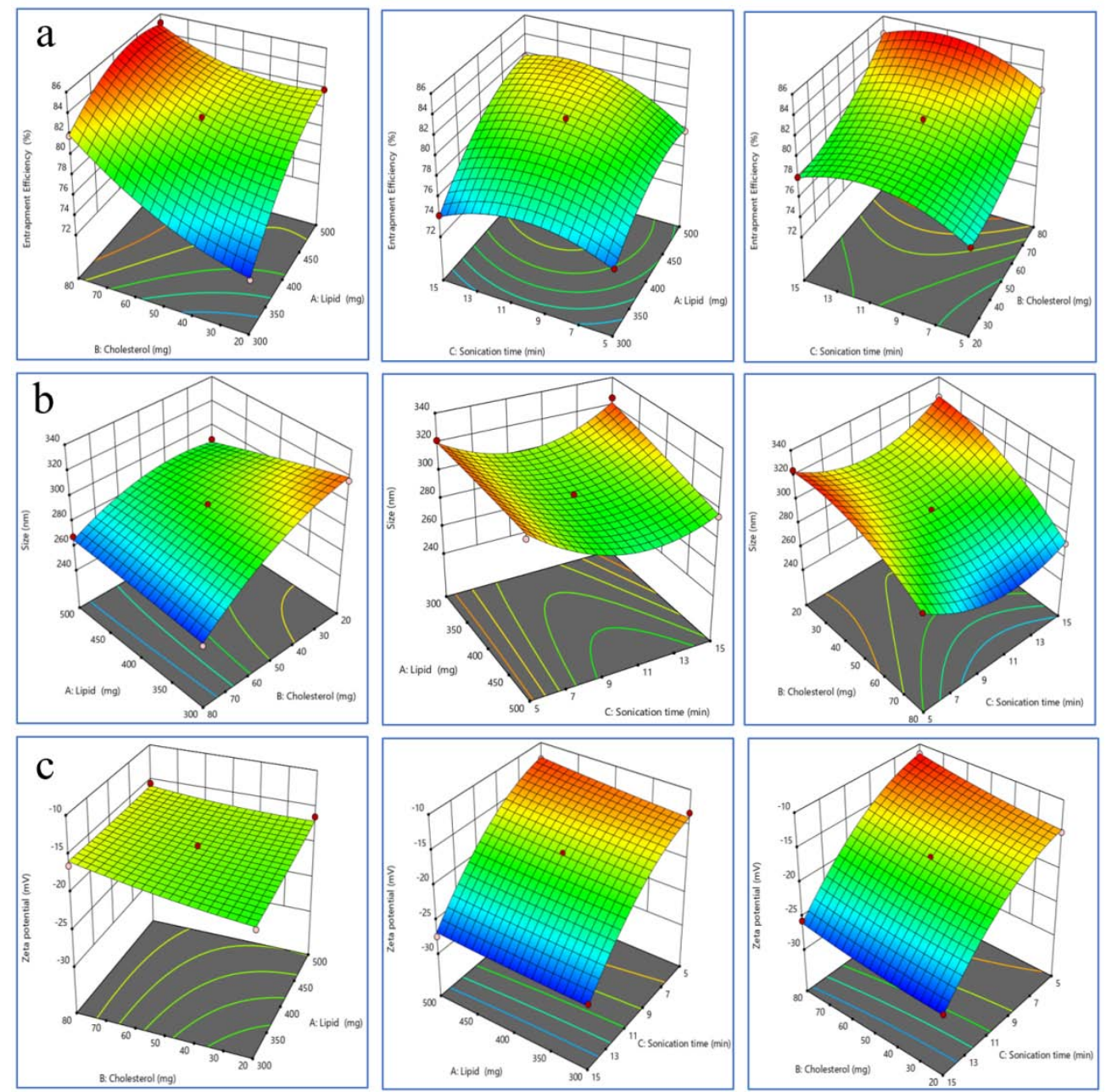

Fig. 1: 3D-response surface plot showing the effect of independent variables on (a) Entrapment efficiency, (b) Size, and (c) Zeta potential 
Table 2: Observed responses in BBD design for optimization of liposomes

\begin{tabular}{|c|c|c|c|c|c|c|}
\hline \multirow[t]{2}{*}{ Run } & Factor 1 & Factor 2 & Factor 3 & Response 1 & Response 2 & Response 3 \\
\hline & A: lipid (mg) & $\begin{array}{l}\text { B: Cholesterol } \\
\text { (mg) }\end{array}$ & $\begin{array}{l}\text { C: Sonication time } \\
\text { (min) }\end{array}$ & $\begin{array}{l}\text { Entrapment efficiency } \\
(\%)\end{array}$ & Size (nm) & Zeta potential $(\mathrm{mV})$ \\
\hline 1 & 500 & 80 & 10 & $85.1 \pm 0.78$ & $268.25 \pm 11.62$ & $-15.53 \pm 2.53$ \\
\hline 2 & 500 & 50 & 5 & $77.8 \pm 0.50$ & $314.63 \pm 7.46$ & $-12.42 \pm 0.50$ \\
\hline 3 & 300 & 50 & 5 & $74.2 \pm 0.70$ & $321.45 \pm 14.30$ & $-13.24 \pm 1.12$ \\
\hline 4 & 300 & 80 & 10 & $81.9 \pm 1.07$ & $258.33 \pm 11.36$ & $-16.42 \pm 1.89$ \\
\hline 5 & 400 & 20 & 15 & $78.1 \pm 1.54$ & $323.85 \pm 25.70$ & $-27.53 \pm 1.32$ \\
\hline 6 & 400 & 50 & 10 & $81.4 \pm 1.04$ & $293.65 \pm 18.16$ & $-17.64 \pm 1.09$ \\
\hline 7 & 500 & 50 & 15 & $81.7 \pm 1.68$ & $295.37 \pm 17.48$ & $-27.42 \pm 0.62$ \\
\hline 8 & 300 & 20 & 10 & $72.9 \pm 1.23$ & $316.72 \pm 18.61$ & $-19.54 \pm 2.06$ \\
\hline 9 & 400 & 80 & 15 & $84.2 \pm 1.25$ & $272.39 \pm 10.54$ & $-25.59 \pm 2.13$ \\
\hline 10 & 400 & 20 & 5 & $76.3 \pm 0.40$ & $324.35 \pm 14.25$ & $-14.52 \pm 0.44$ \\
\hline 11 & 500 & 20 & 10 & $81.9 \pm 1.06$ & $288.97 \pm 32.31$ & $-16.33 \pm 1.10$ \\
\hline 12 & 300 & 50 & 15 & $74.2 \pm 1.82$ & $325.32 \pm 10.82$ & $-26.99 \pm 1.30$ \\
\hline 13 & 400 & 50 & 10 & $80.8 \pm 2.86$ & $294.22 \pm 16.21$ & $-17.13 \pm 0.17$ \\
\hline 14 & 400 & 50 & 10 & $80.6 \pm 1.36$ & $296.74 \pm 19.23$ & $-17.52 \pm 1.12$ \\
\hline 15 & 400 & 80 & 5 & $82.1 \pm 1.25$ & $293.76 \pm 6.49$ & $-11.46 \pm 1.95$ \\
\hline
\end{tabular}

$\pm \mathrm{SD}(\mathrm{n}=3)$ of three determinations

Table 3: Summary results of regression analysis, SD, and \%CV with responses Y1, Y2, and Y3 for the quadratic model equation

\begin{tabular}{lllll}
\hline Quadratic model & $\mathbf{R}^{\mathbf{2}}$ & Adjusted R & Predicted R $^{\mathbf{2}}$ & SD $^{\mathbf{0}}$ \\
\hline Entrapment efficiency (\%) & 0.9974 & 0.9927 & 0.9829 & 0.31 \\
Size (nm) & 0.9913 & 0.9757 & 0.8725 & 3.36 \\
Zeta potential (mV) & 0.9946 & 0.9850 & 0.9188 & 1.12 \\
\hline
\end{tabular}

SD-Standard deviation; CV-Coefficient of variation

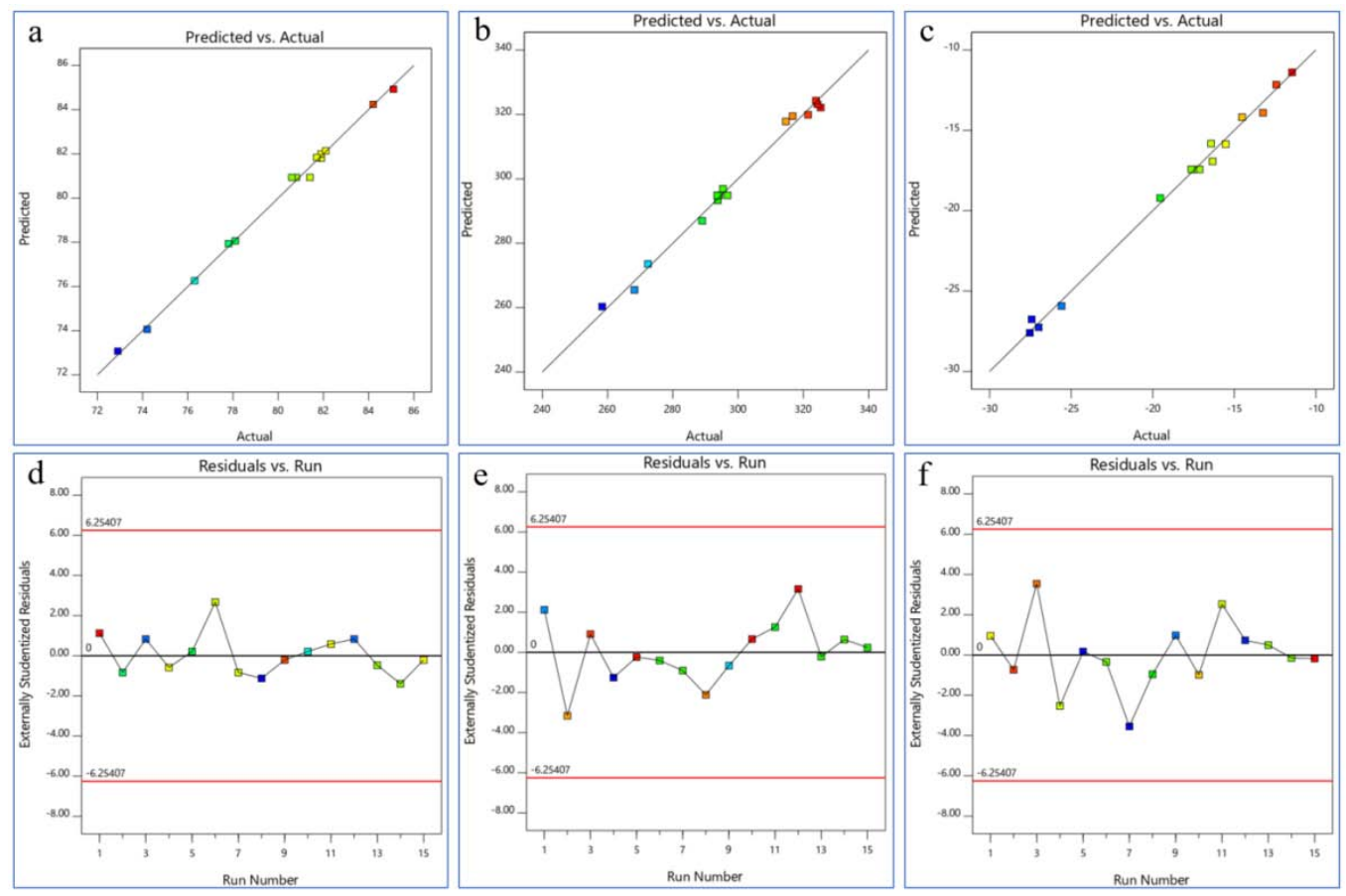

Fig. 2: Linear correlation plots $(a, b, c)$ between actual and predicted values and the corresponding residual plots (d, e, f) for entrapment efficiency, size and zeta potential, respectively

\section{Transmission electron microscopy (TEM)}

The optimized liposomes were examined by TEM and appeared predominantly spherical in shape and had uniform size distribution. The surface of the liposome was found to be bilayer, smooth and regular. The aggregation of vesicles was not observed. The shape and surface morphology analysis indicated the stability of the prepared liposomes [27].

\section{In vitro release studies}

The optimized liposomes showed better release; initially, the drug releases rapidly from the lipid surface, following the slow release of the drug owing to degradation of the lipid core. The maximum release was found to be $98.43 \pm 1.2 \%$ up to $24 \mathrm{~h}$. The in vitro drug release plot was shown in fig. 4 . The $\mathrm{R}^{2}$ zero-order kinetics and Korsmeyer-Peppas model were found to be 0.9919 and 0.9664 , respectively [28]. The 
zero-order shows the best fit model with the highest $\mathrm{R}^{2}$ value exhibiting better correlation and the ' $n$ ' value was also found to be 0.85 ; this lies between 0.43 and 0.85 , an indication of both diffusion- controlled and swelling-controlled drugs release that is anomalous transport $[29,30]$.
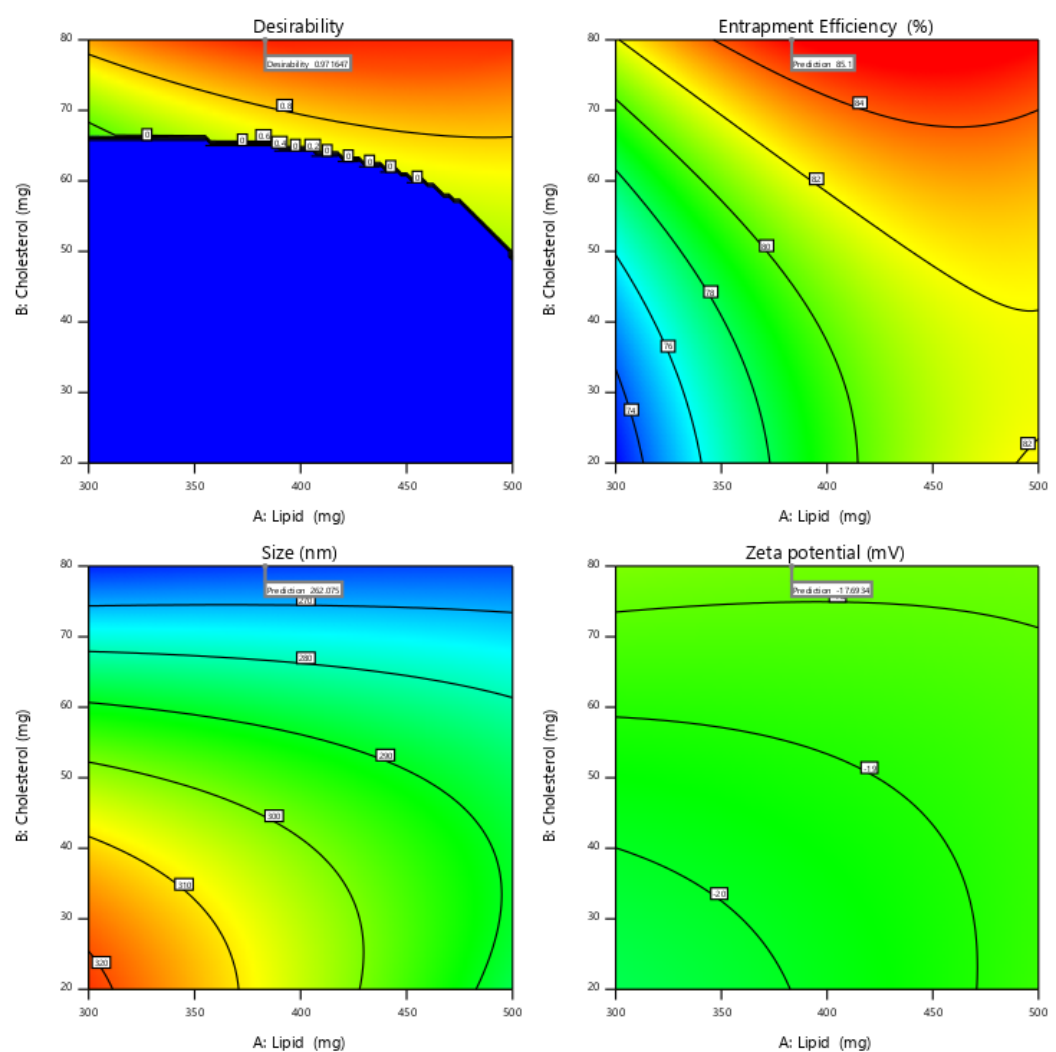

Fig. 3: Contour plot of the optimized formulation

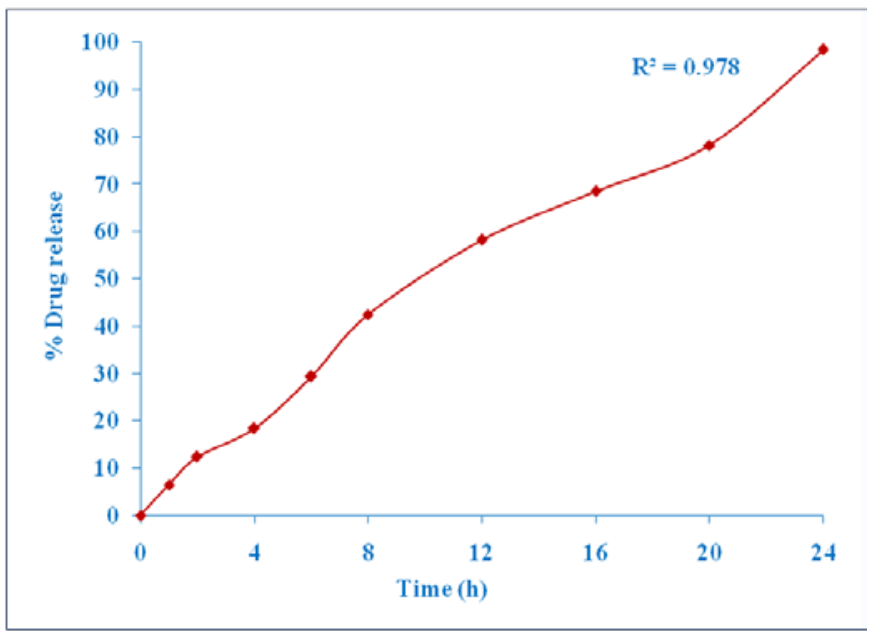

Fig. 4: In vitro drug release of the optimized formulation

\section{CONCLUSION}

$\mathrm{OZ}$ in the form of liposomes could be successfully used for delivering to the brain through nasal administration. Design-Expert ${ }^{\circledR}$ Software assisted in designing the experimental protocol in optimizing the formulations. The liposomes were discrete spherical vesicles with the smooth bilayered surface with optimum size and surface charges. The drug releases further support and proves to have a better-controlled release for $24 \mathrm{~h}$. Hence, the formulation supports in all aspects and meet the in vitro characterization in the process of targeting the brain through nasal delivery.

\section{ACKNOWLEDGMENT}

The author is thankful to JNTUA-OTPRI, Ananthapuramu for providing the laboratory facilities, chemicals to carry out the research work.

\section{FUNDING}




\section{AUTHORS CONTRIBUTIONS}

All authors have contributed equally.

\section{CONFLICTS OF INTERESTS}

The authors declared that they have no conflicts of interest.

\section{REFERENCES}

1. Gaebel W, Zielasek J. Schizophrenia in 2020: trends in diagnosis and therapy. Psychiatry Clin Neurosci 2015;69:661-73.

2. Valencia M, Fresan A, Juarez F, Escamilla R, Saracco R. The beneficial effects of combining pharmacological and psychosocial treatment on remission and functional outcome in outpatients with schizophrenia. J Psychiatr Res 2013;47:1886-92.

3. Howard P, Twycross R, Shuster J, Mihalyo M, Wilcock A. Antipsychotics. J Pain Symptom Manag 2011;41:956-65.

4. Larsen JM, Martin DR, Byrne ME. Recent advances in delivery through the blood-brain barrier. Curr Top Med Chem 2014;14:1148-60.

5. Silva AC, Gonzalez Mira E, Sousa Lobo JM, Amaral MH. Current progresses on nano delivery systems for the treatment of neuropsychiatric diseases: alzheimer's and schizophrenia. Curr Pharm Des 2013;19:7185-95.

6. Yogesh S Thorat, Nagesh S Kote, Virendra V Patil, Avinash H Hosmani. Formulation and evaluation of liposomal gel containing extract of piprine. Int J Curr Pharm Res 2020;12:126-9.

7. Mittal D, Ali A, Md S, Baboota S, Sahni JK, Ali J. Insights into the direct nose to brain delivery: current status and future perspective. Drug Delivery 2014;21:75-86.

8. Kozlovskaya L, Abou Kaoud M, Stepensky D. Quantitative analysis of drug delivery to the brain via nasal route. J Controlled Release 2014;189:133-40.

9. Leonor Pinzon Daza M, Campia I, Kopecka J, Garzon R, Ghigo D, Riganti C. Nanoparticle-and liposome-carried drugs: new strategies for active targeting and drug delivery across bloodbrain barrier. Curr Drug Metab 2013;14:625-40.

10. Seju U, Kumar A, Sawant KK. Development and evaluation of olanzapine-loaded PLGA nanoparticles for nose-to-brain delivery: in vitro and in vivo studies. Acta Biomaterialia 2011;7:4169-76.

11. Jafari S, Bouillon ME, Huang XF, Pyne SG, Fernandez Enright F. Novel olanzapine analogues presenting a reduced $\mathrm{H} 1$ receptor affinity and retained 5HT2A/D2 binding affinity ratio. BMC Pharmacol 2012;12:1-8.

12. Srivastava S, Ketter TA. Clinical relevance of treatments for acute bipolar disorder: balancing therapeutic and adverse effects. Clin Ther 2011;33:B40-48.

13. Altamura AC, Sassella F, Santini A, Montresor C, Fumagalli S, Mundo E. Intramuscular preparations of antipsychotics: uses and relevance in clinical practice. Drugs 2003;63:493-512.

14. Rahul Tiwaria, Kaliyaperumal Viswanathanb, Suresh Prasad Vyasa, Vandana Soni. In vitro evaluation of lectinized cisplatin bearing liposomes system. Int J Appl Pharm 2020;12:60-4.

15. Reema Narayan, Mohan Singh, Om Prakash Ranjan, Yogendra Nayak, Sanjay Garg, Gopal V Shavi, et al. Development of risperidone liposomes for brain targeting through intranasal route. Life Sci 2016;163:38-45.

16. Ajay Kumar, Shital Badde, Ravindra Kamble, Varsha B Pokharkar. Development and characterization of liposomal drug delivery system for nimesulide. Int J Pharm Pharm Sci 2010;2:87-9.

17. Ramkanth S, Anitha $P$, Gayathri R, Mohan S, Dinesh Babu. Formulation and design optimization of nano-transferosomes using pioglitazone and eprosartan mesylate for concomitant therapy against diabetes and hypertension. Eur J Pharm Sci 2021;162:105811.

18. Rompicharla S, Bhatt H, Shah A, Komanduri N, Vijayasarathy D, Ghosh B, et al. Formulation optimization, characterization, and evaluation of in vitro cytotoxic potential of curcumin loaded solid lipid nanoparticles for improved anticancer activity. Chem Phys Lipids 2017;208:10-8.

19. Girish Sailor, Seth AK, Ghanshyam Parmar, Sachin Chauhan, Ankur Javia. Formulation and in vitro evaluation of berberinecontaining liposome optimized by 32 full factorial designs. J Appl Pharm Sci 2015;5:23-8.

20. Tefas LR, Muntean DM, Vlase L. Quercetin-loaded liposomes: formulation optimization through a D-optimal experimental design. Farmacia 2015;63:26-33.

21. Colletier JP, Chaize B, Winterhalter M. Protein encapsulation in liposomes: efficiency depends on interactions between protein and phospholipid bilayer. BMC Biotechnol 2002;2:9.

22. Jaafar Maalej C, Diab R, Andrieu V. Ethanol injection method for hydrophilic and lipophilic drug-loaded liposome preparation. J Liposome Res 2010;20:228-43.

23. Chavan SS, Ingle SG, Vavia PR. Preparation and characterization of solid lipid nanoparticle-based nasal spray of budesonide. Drug Delivery Transl Res 2013;3:402-8.

24. Nagayasu V, Uchiyama K, Kiwada H. The size of liposomes: a factor which affects their targeting efficiency to tumors and therapeutic activity of liposomal antitumor drugs. Adv Drug Delivery Rev 1999;40:75-87.

25. Garg A, Bhalala K, Tomar DS. In-situ single pass intestinal permeability and pharmacokinetic study of developed lumefantrine loaded solid lipid nanoparticles. Int J Pharm 2017;516:120-30.

26. Junyaprasert VB, Teeranachaideekul V, Supaperm T. Effect of charged and non-ionic membrane additives on physicochemical properties and stability of niosomes. AAPS PharmSciTech 2008;9:851-9.

27. Vakili Ghartavol R, Rezayat SM, Faridi Majidi R. Optimization of docetaxel loading conditions in liposomes: proposing potential products for metastatic breast carcinoma chemotherapy. Sci Rep 2020;10:5569.

28. Vali AM, Toliyat T, Shafaghi B, Dadashzadeh S. Preparation, optimization, and characterization of topotecan loaded PEGylated liposomes using factorial design. Drug Dev Ind Pharm 2008;34:10-23.

29. Shabnam, Prathima Srinivas, Ravindra Babu DS. Formulation and evaluation of parenteral methotrexate nanoliposomes. Int J Pharm Pharm Sci 2014;11:295-300.

30. Bhavin K Patel, Rajesh H Parikh. Formulation development and evaluation of temozolomide loaded hydrogenated soya phosphatidylcholine liposomes for the treatment of brain cancer. Asian J Pharm Clin Res 2016;9:240-3. 